\title{
Osteological Study on the Effect of Trichloroethylene on the Axial Skeletal System of Maternally Treated 18-Day-Old Albino Mice Fetuses
}

\author{
Abou Rashed NM ${ }^{1}$, El-Shershaby $\mathrm{AM}^{2}$, El-Balshy RM ${ }^{3}$, Abd El-Hady $\mathrm{SI}^{4}$ \\ Dept of Zoology, Faculty of Science, Benha University, Egypt ${ }^{1,3,4}$ \\ Dept of Zoology, Faculty of Science, Cairo University, Egypt ${ }^{2}$
}

\begin{abstract}
The present study investigates the effects of different doses of "trichloroethylene" TCE on the axial and appendicular skeleton of day 18 mice fetuses maternally treated with TCE. The experimental females (90 virgin females) were divided into three groups; the first one (G1) was the control that treated with the solvent only (corn oil), the second (G2) and the third (G3) treated groups with low (24 mg/kg) and high ( $240 \mathrm{mg} / \mathrm{kg})$ doses of TCE, respectively. Oral administration of TCE to female mice once daily for a period of 21 days before mating and till $17^{\text {th }}$ day of pregnancy, caused a significant decrease in the body weight and body length of treated fetuses. Stereoscopic examination for the obtained $18^{\text {th }}$ day fetuses showed severe skeletal alterations included incomplete ossification for some bones of skull, vertebrae, fore and hind limbs and significant reduction in the length of most long bones of both limbs. These alterations indicated that TCE treatment induced growth retardation confirmed by great reduction in body weight and body length. The results suggest that TCE has teratogenic effects on maternally treated 18-day-old albino mice fetuses.
\end{abstract}

Keywords: trichloroethylene, skeletal system, teratogenicity, 18-day-old Albino mice fetuses.

\section{INTRODUCTION}

Trichloroethylene (TCE) is a chlorinated hydrocarbon, not naturally found in the environment (man-made); it is an environmental toxicant due to production, use and disposal. TCE is detectable in underground water sources, surface water, and the air (Ugden et al., 1983). TCE is produced in the petrochemical industry and has many uses, such as in dry cleaning operations, paint and printing ink removal, fumigation of rodents, manufacturing fluorocarbons, beverages (decaffeination of coffee), pet foods, medicine, pharmaceuticals, cosmetics and as an anesthetic agent (Kaneko et al., 1997; IARC, 1995; Maull et al., 1997). In addition, it is used in the pharmaceutical industry as a solvent for waxes, fats, resins, and oils and in the aerospace industry for flushing liquid oxygen. Trichloroethylene is readily absorbed following both oral and inhalation exposures. It is also absorbed from the gastrointestinal tract into the systemic circulation in animals. Using radiolabelled TCE, Mass balance studies indicated that mice and rats metabolized TCE at $38.10 \%$ and $15.10 \%$, respectively, following oral administration in corn oil vehicle. For both species, the lower values were obtained following treatment with large doses in excess of $1000 \mathrm{mg} / \mathrm{kg} \mathrm{b}$.wt, implying that the rate of absorption was higher at low doses than at high doses in both species (Mitoma et al., 1985; Prout et al., 1985 and Rouisse \& Chakrabarti, 1986). Once absorbed, TCE diffuses readily across biological membranes and is widely distributed to tissues and organs via the circulatory system. Studies in animals (Fernandez et al., 1977; Fisher et al., 1991) and humans (De Baere et al., 1997) have found TCE or its metabolites in most major organs and tissues. Also, TCE may accumulate in adipose tissue because of its lipid solubility. Consequently, slow release of TCE from adipose stores might act as an internal source of exposure, ultimately resulting in longer mean residence times and bioavailability of TCE (Dallas et al., 1991; Fisher et al., 1991). The oxidative metabolism of TCE occurs primarily in the liver, although it may also occur in other tissues, particularly the kidney and the lung. There are two main pathways responsible for TCE metabolism: oxidation by cytochrome P-450 and conjugation with glutathione (GSH) by glutathione-S-transferases (Lash et al., 2000).

\section{MATERIALS AND METHODS}

\subsection{Animals}

Ninety virgin female and thirty fertile male albino mice weighing approximately 23-25 gm were used for experimentation. The animals were arranged into three groups, each was composed of 30 females as follows: The first group (G1), in which the animals were treated under the same condition with the dose solvent (corn oil). The second group (G2) and the third group (G3) in which females were treated orally for three weeks (daily) with 24 $\mathrm{mg} / \mathrm{kg}$ and $240 \mathrm{mg} / \mathrm{kg}$ body weight of TCE, respectively. The treated females allowed mating with normal male. 


\subsection{Mating procedures}

The females which were found at the pro-estrus stage were selected, each three of them were kept with one adult male in one cage overnight. Occurrence of copulation was established in the next morning at $9.00 \mathrm{a}$.m. by the presence of the vaginal plug and/or the presence of the sperms in the vaginal smear, and this day was considered to be the first day of pregnancy, assuming coitus took place at 1.0 a.m. on the night of mating (Terada and Nishimura, 1975). The treated pregnant females received TCE until $17^{\text {th }}$ day of gestation and sacrificed on day 18 of pregnancy.

\subsection{Administration of trichloroethylene}

Highest purity trichloroethylene (TCE) obtained from Sigma-Aldrich company at Cairo was used in the present work. The used dose was based upon the 50\% lethal dose $\left(\mathbf{L D}_{50}\right)$ value of $2402 \mathrm{mg} / \mathrm{kg}$ body weight in mice taken from the Registry for Toxic Effects of Chemical Substances (Tucker et al.1982). The two doses of TCE investigated in the present study were 24 and $240 \mathrm{mg} / \mathrm{kg}(1 / 100$ as low dose and 1/10 of LD50 as a high dose, respectively) dissolved in corn oil. Control doses consist of corn oil only. The used doses were made up immediately preceding dosing and a volume of $0.2 \mathrm{ml}$ was given per animal. Mice were administered TCE using an 18 -gauge, $3.8 \mathrm{~cm}$ curved gavage needle attached to a graded glass syringe. Food was withheld from all animals for 4 hours prior to daily administration. The full gravid uteri dissected to extract the 18th day fetuses, washed in saline and then stained with a double stain; Alizarin R-S and Alcian blue. Then preserved in pure glycerol for examine by stereo microscope and photograph.

\section{RESULTS}

\section{External morphological studies}

In the present investigation the external morphological examination indicated that, TCE causes growth retardation of the fetuses. Growth retardation is indicated by the reduction in fetal body weight and length (Fig.1). The decreasing of both weight and length of the fetuses $\left(18^{\text {th }}\right.$ day of gestation) maternally treated with low dose TCE (G2) showed non-significant decrease. However, significant decrease values were calculated in the experimental group (G3) where, body weight and crown- rump length attained considerable reduction (Fig. 1).

\section{Osteological studies}

Trichloroethylene (TCE) affected the development of skeletal system of treated foetuses at the 18th day of gestation as compared with the normal one at the same age. This effect included the shortage in lengths of bones and decrement of bones and cartilages of the skeletal system as the following:

\section{The axial skeleton}

\section{1- The skull}

The well-ossified dermal bones of the skull of control foetuses at 18th day of gestation are paired nasal act as a roof for the nasal capsules, followed posteriorly by the paired frontals and the paired parietals. A small triangular interparietal bone is present in between the posterior ends of the parietals. The bones of the maxillary arch consist of a premaxilla, ventral to the anterior nares, maxilla forming the lateral side of the facial region of the skull, jugal which is forming the anterior part of the zygomatic arch and squamosal completing zygomatic arch at the posterior edge of the skull (Fig. 2A). Also, the ossification of each vomer, pterygoid and palatine with its processes; palatal process of palatine and palatine process of maxilla to form the floor of the skull (Fig. 2A). However, the dentary bone of the lower jaw is completely ossified and it envelopes the Mechel's cartilages which still cartilaginous and are united anteriorly to form symphesis meckelii (Figs 2A).

Also, the cartilaginous bones (replacing bones) of the skull which are included the basioccipital, exoccipitals, basisphenoid, presphenoid, and orbitosphenoid, which are clearly ossified. At the same time some of cartilaginous bones such as orbitosphenoid, ethmoid, tympanic bulla, periodic are not yet ossified while the supraoccipital is partially ossified (Fig. 2A).

Foetuses at the 18th day of gestation of the G2 \& G3 have exhibited several skeletal alterations. The bones of the skull of the two treated groups have a gradual decrement of the volume and length as compared to control group (Figs 2A, B, C). These changes included decrease of ossification of both cartilaginous and dermal bones of the skull for both treated groups. In relation to the change in length and volume of the skull of the treated foetuses of second group which subjected to severe abnormalities, this lead to a clear shortage in length and volume of this skull as compared with the normal group and first treated one (Figs 2A, $\mathrm{B}, \mathrm{C})$. The dermal bones of the first treated group have been disappeared such as nasal, frontal, parietal, interparietal, squamosal, vomer, palatine and its process, pterygoid and dentary. Also, the cartilaginous bone for the same group minimized in volume or disappeared such as exoccipital, basioccipital, basisphenoid and supraoccipital (Fig. 2). In relation to the second treated group, the shape and volume of skull has a clear shortage and not ossified the most bones including dermal and cartilaginous one, except pterygoid, basisphenoid and basioccipital as compared the control skull with that of second group. The bone of the lower jaw has a gradual lack of ossification as can be shown from figure 3 , since there is a slight ossification for dentary of first group, while there is completely disappearing for this bone in case of second group. This case as can be shown from figure $3 \mathrm{G} 2$, the lower jaw consists of Meckel's cartilage and some connective tissue around it.

\section{The vertebral column}

The vertebral column of control mouse foetuses at 18th day of gestation is composed of seven cervical, 13 thoracic, six lumber, four sacral and caudal vertebrae. Also, the centra and neural arches of most vertebrae are clearly ossified, while most of the last caudal vertebrae are still nonossified. The neural arches of the thoracic and lumbar vertebrae are still separated while those of the sacral vertebrae are just fused. 
Examination of the vertebrae of the experimental group G2 indicated to gradual unossified parts of vertebrae such as centra of cervical vertebrae number $1,2,6$, and seven and the other centra are less ossified (Fig. 4G1). But in case of second group $\mathrm{G} 2$, all centra are completely unossified (Fig. 4G2). However, the lateral edges of transverse process of cervical vertebrae are not ossified in G2 and G3 except the 6th and 7th vertebrae of G3 (Fig. 4G1 \& G2).

Studying of the thoracic vertebrae revealed that there is no effect on the centra and transverse process of these vertebrae of first group as compared with those of control one (Fig.5). Moreover, in second group the centrum of first and second vertebrae is completely disappeared while the rest of centra of vertebrae are reduced in size (Fig. 5G2). Also, in the same group the transverse process is more reduced for all thoracic vertebrae as compared with the control one (Fig. 5C).

At the same times, the centra and transverse process for every lumbar vertebrae of foetuses at 18th day of gestation maternally treated with low dose of TCE (G1) and high dose of TCE (G3) showed gradually decrease in ossification in contrast with the control group (Fig. 6). From this comparison, the cartilaginous material becomes dominant for the components of lumbar vertebrae of second group especially the neural arches.

\section{The Sternum and Ribs}

The sternum of the control foetuses consists of six rod-like pieces of well-ossified sternabrae arranged in a straight line (Fig. 7C). The sternabrae of G2 are less ossified and decrease in length and diameter as compared with the control group. However, the effect of trichloroethylene with a high dose on the sternal components of foetuses at 18th day of gestation (second group) leads to completely devoided from bony material (becoming cartilaginous phase) and the sternabrae become narrower than the other previous groups; control and first groups.

The control foetuses (18th day of gestation) possess 13 pairs of ribs. Each rib consists of a bony vertebral portion and a cartilaginous sternal one. The sternal parts of the ribs, except the last three pairs, articulate with the sternum. The ribs which reach the ventral side are independently attached to the breast bone are named as a true ribs. The unattached ribs are called false or floating ribs (Fig. 8C).

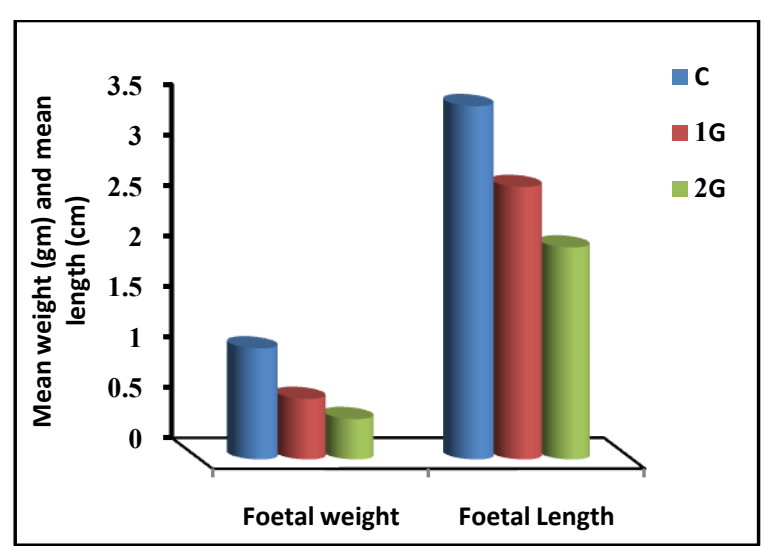

Fig. (1): The mean of fetal weight and length of control and maternally treated fetuses.
The ribs of foetuses of G1 appeared, more or less, well ossified as compared with the control one. Also, the sternal portion of last three ribs appeared as wavy shaped (Fig. $8 \mathrm{G} 1)$. But those of $\mathrm{G} 2$ exhibited obviously regression of ossification process for the most part of vertebral portion of ribs. The phenomenon of wavy sternal portion of ribs is found in last six ribs as can be shown from figure $8 \mathrm{G} 2$.

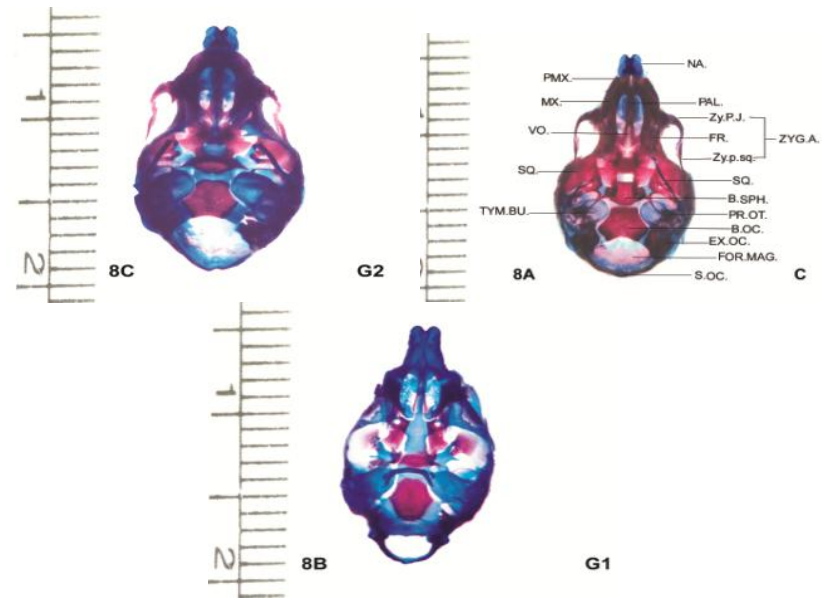

Fig. (2) : Photographs of ventral view of the skull of foetuses on 18th day of gestation showing skull alterations. (C): skull of control foetus showing ossified elements. (G1): skull of foetuses from dams treated with low dose of TCE showing incomplete ossification and complete nonossified elements. (G2) : skull of foetuses from dams treated with high dose of TCE showing completely nonossified elements. Note: in all cases (B \& C) the tympanic pullae are completely non-ossified as the control.

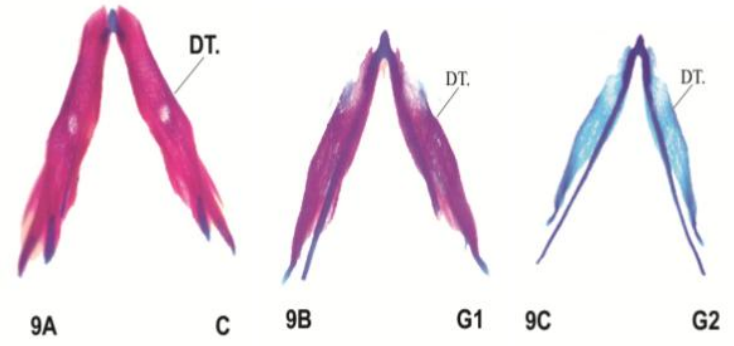

Fig. (3) : photographs of dorsal view of the lower jaw of foetuses at 18th day of gestation showing gradual decrease in ossification of dentry bone from the control (C) to low (G1) and high dose (G2) of TCE treatment. Note: highly reduced in the size of dentry bone that is completely nonossified.

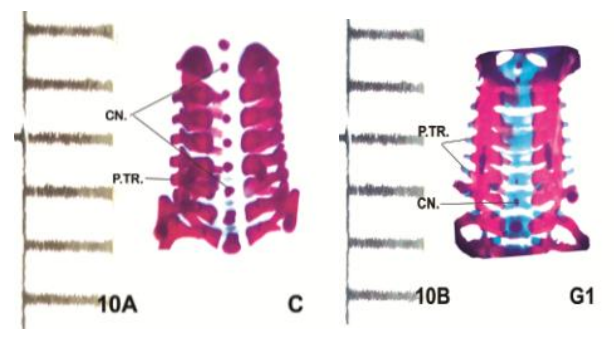


Vol. 4, Issue 3, March 2017

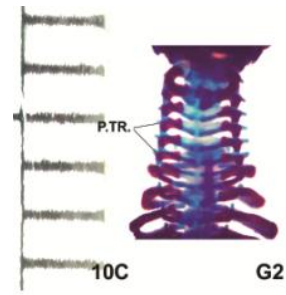

Fig. (4): Photographs of ventral view of the cervical vertebrae of mouse foetuses at 18th day of gestation showing alterations of the vertebrae. (C): Foetuses from control dam showing seven well ossified vertebrae, as well as the centra and transverse processes. (G1): foetuses from dam treated with low dose of TCE showing that the centra of vertebrae number 1, 2, 3 and 4 are completely non-ossified and number 5, 6 and 7 are partially ossified and partially cartilaginous. (G2): foetuses from dam treated with high dose of TCE showing that all the seven vertebrae together with the lateral edges of transverse processes are nonossified except the 6th and 7th vertebrae.
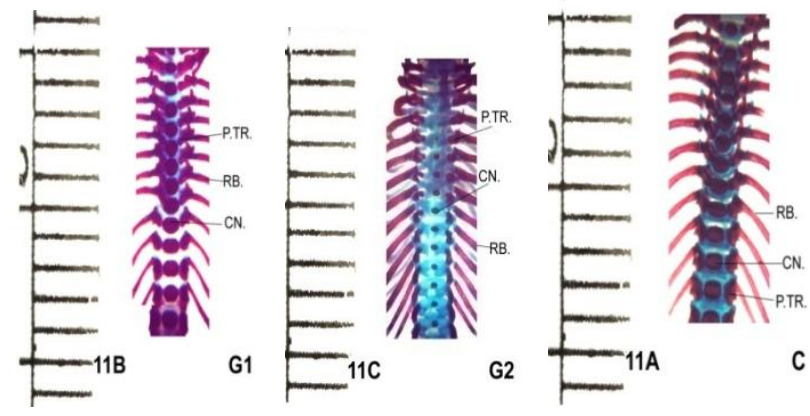

Fig. (5): photographs of ventral view of the thoracic vertebrae of mouse foetuses at 18th day of gestation showing alterations of the vertebrae. (C): Foetuses from control dam showing well ossified vertebrae, centra and transverse processes. (G1): Foetuses from dam treated with low dose of TCE showing well ossified centra with decreased size of the transverse processes. (G2): Foetuses from dam treated with high dose of TCE showing that the centra of vertebrae number 1 and 2 are completely disappeared, while those of the rest of vertebrae are highly decreases in size.

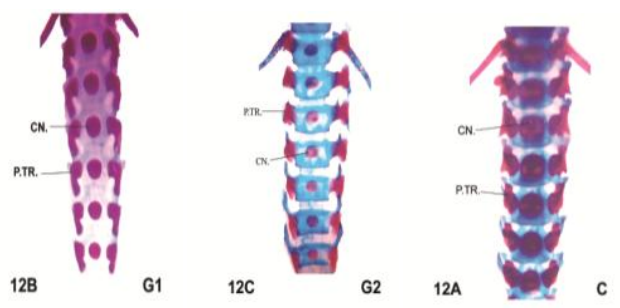

Fig.(6) : photographs of ventral view of the lumbar vertebrae of mouse foetuses at 18th day of gestation showing alterations of the vertebrae. (C): Foetuses from control dam showing well ossified vertebrae and arches. (G1): Foetuses from dam treated with low dose of TCE showing well ossified vertebrae with a decrease in the size of the centra and transverse processes. (G2): Foetuses from dam treated with high dose of TCE showing less ossified vertebrae and centra. The centra and transverse processes are reduced in size.

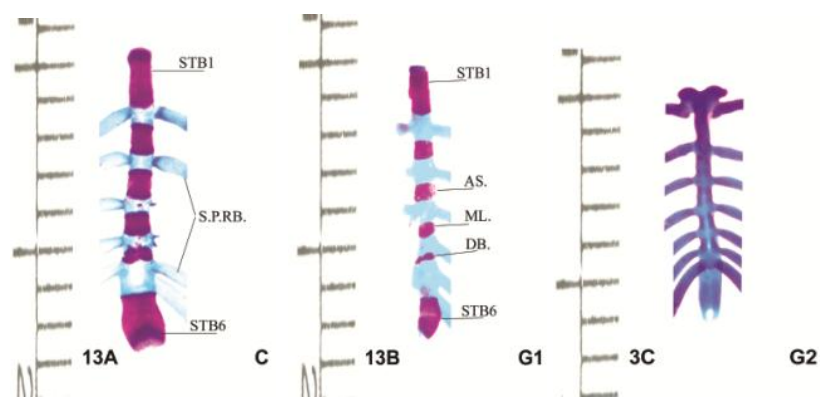

Fig. (7): Photographs of ventral view of the sternum of mouse foetuses at 18 th day of gestation showing alterations of the sternum. (C): Foetuses from control dam showing well ossified sternebrae (st1-st6). (G1): Foetuses from dam treated with low dose of TCE showing less ossified sternebrae. Note : asymmetric (As), dumb-bell shaped (Db) and malaligned (Ml) sternebrae. (G2): Foetuses from dam treated with high dose TCE showing completely chondrified sternebrae. Note : separation of the 5 th and 6 th sternebrae.

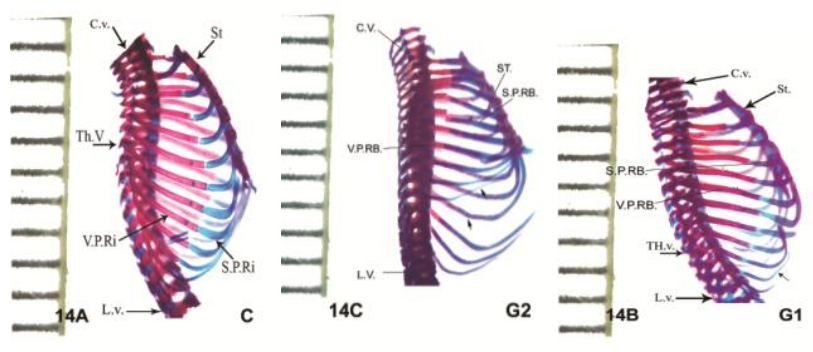

Fig. (8): Photographs of lateral view of the ribs of mouse foetuses at 18th day of gestation showing alterations of the ribs. (C): Foetuses from control dam showing well ossified vertebral portions of the ribs and chondrified portions. (G1): Foetuses from dam treated with low dose of TCE showing less ossified vertebral portions of the ribs. Note: wavy sternal portions of ribs number 10 and 11. (G2): Foetuses from dams treated with high dose of TCE showing reduction in ossification of the vertebral portions of ribs, fusion of vertebral portions of ribs number 2 and 3 and wavy appearance of the sternal portions of ribs number 9 and 10 .

\section{DISCUSSION}

The present investigation has revealed that on day 18 of fetal life, chondrogenesis and ossification of axial skeletons were complete nearly in most control fetuses examined. In addition, the development of ribs and sternebrae was complete too. These findings are in line with those offered by Taylor (1986).

In the present study skeletal preparations of 18-day-old mice fetuses maternally treated with low and high dose of 
TCE (G2 and G3, respectively) showed growth retardation of the skeletal elements represented by incomplete or sever lack of ossification of some bones in the skull, vertebrae, sternal elements, shortness of ribs and complete nonossification of some others, i.e., bones of the skull, vertebrae and bones of sternum. The results of this study showed a significant reduction in the fetal body weight and length of G3 as compared with the control one (G1). In this concern, similar findings were reported by Carney et al., (2006) when exposed female rats to $600 \mathrm{ppm}$ TCE during gestational days from 6 to 9 . Also, these results in agreement with Schwetz et al., (1975), Dorfmueller et al., (1979) and Das \& Scott (1994). Schwetz et al., (1974) reported that inhaled $300 \mathrm{ppm}$ TCE for $7 \mathrm{hr}$ daily on days 6-15 of gestation by pregnant female mice lead to delayed ossification of skull bones and split sternebrae (unfused centers of ossification) and delayed ossification of sternebrae was significantly greater than in controls.

Growth retardation of skeletal elements observed in the present investigation may be attributed to the inhibition of protein synthesis in the tissues of developing embryo during the active period of growth (Mazzullo et al., 1992; Wu \& Berger, $2007 \& 2008)$. Where, oxidative metabolism of TCE generates a variety of reactive intermediates, including the unstable epoxide 2,2,3-trichlorooxirane and TCEoxide (Cai \& Guengerich 2001), oxygen-free radicals (Steele-Goodwin et al., 1996), and trichlorinated carboncentered radicals ( $\mathrm{Ni}$ et al., 1996). Reactive oxygen species (ROS) and radicals can damage cellular components (Khan et al., 2009), resulting in increased protein turnover, decreased protein function, lipid peroxidation (Stadtman \& Oliver 1991). It is also probable that TCE may affect calcium content of pregnant mothers and/or decrease the rate of calcium absorption.

The retarded skeletal elements may be attributed to transplacental passage of TCE or its metabolites (Laham, 1970 and Withey \& Karpinski, 1985) and its direct or indirect effects on the differentiation of skeletal elements or via adverse effects on maternal liver \& kidney leading to impairment of vitamin $\mathrm{D}$ involved in calcium metabolism and consequently retarded skeleton formation.

As a general, it could be stated that one or more of the previously mentioned factors stand at the principal causal agent of incomplete ossification of the skeletal elements. This suggestion is in accordance with the statement presented by Ganong (1995) who mentioned that adequate amounts of both protein and minerals must be available for the maintenance of normal bone structure. However, it is important to note that these skeletal variants are indicative of a delay in development and are consistent with the significantly decrease fetal body measurements and growth which were observed in these fetuses.

\section{CONCLUSIONS}

The results obtained from 18-day-old fetuses maternally treated with TCE showed that TCE has teratogenic effects on skeletal development and the degree of these effects depends upon the level and duration of the dose.

\section{ACKNOWLEDGEMENT}

The authors would like to thank the staff member of Zoology Department, Faculty of Science, Benha University, for the help offered me through the preparation of this manuscript.

\section{REFERENCES}

[1] Ugden, P.C. and Miller, J.W. (1983): Chlorinated acids and chloral in drinking water. J. Am. Water Works Assoc., 75: 524 -527.

[2] Kaneko, T.; Wang, P.Y. and Sato, A. (1997): Assessment of the health effects of trichloroethylene. Ind. Health, 35: 301-324.

[3] Stadtman, E.R. and Oliver, C.N. (1991): Metal-catalyzed oxidation of proteins. Physiological consequences. J. Biol. Chem., 266(4): 2005-2008.

[4] Ni, Y.; Wong, T. and Fu, P.P. (1996): Mouse liver microsomal metabolism of chloral hydrate, trichloroacetic acid and trichloroethanol leading to induction of lipid peroxidation via a free radical mechanism. Drug Metab. Dispos., 24: 81-90.

[5] IARC (International Agency for Research on Cancer). (1995): Trichloroethylene. In IARC Monograph on the Evaluation of the Carcinogenic Risk of Chemicals to Humans. 63: 75-158.

[6] Maull, E.A.; Cogliano, V.J.; Scott, C.S.; Barton, H.A.; Fisher, J.W.; Greenberg, M.; Rhomberg, L. and Sorgen, S.P. (1997): Trichloroethylene health risk assessment: A new and improved process. Drug Chem. Toxicol., 20: 427-442.

[7] Mitoma, C.; Steeger, T.; Jackson, S.E.; Wheeler, K.P.; Rogers, J.H. and Milman, H.A. (1985): Metabolic disposition study of chlorinated hydrocarbons in rats and mice. Drug Chem. Toxicol., 8: 183194.

[8] Prout, M.S.; Provan, W.M. and Green, T. (1985): Species differences in response to trichloroethylene. Pharmacokinetics in rats and mice. Toxicol. Appl. Pharmacol., 79: 389-400.

[9] Rouisse, L. and Chakrabarti, S.K. (1986): Dose-dependent metabolism of trichloroethylene and its relevance to hepatotoxicity in rats. Environ. Res., 40: 450-458.

[10] Fernandez, J.G.; Droz, P.O.; Humbert, B.E. and Caperos, J.R. (1977): Trichloroethylene exposure simulation of uptake, excretion, and metabolism using a mathematical model. Br. J. Ind. Med., 34: 43-55.

[11] Fisher, J.W.; Gargas, M.L.; Allen, B.C. and Andersen, M.E. (1991): Physiologically based pharmacokinetic modeling with trichloroethylene and its metabolite, trichloroacetic acid, in the rat and mouse. Toxicol. Appl. Pharmacol., 109: 183-195.

[12] De-Baere, S.; Meyer, E.; Dirinck, I.; Lambert, W.; Piette, M.; VanPeteghem, C. and De-Leenheer, A. (1997): Tissue distribution of trichloroethylene and its metabolites in a forensic case. Anal. Toxicol., 21: 223-227.

[13] Dallas, C.E.; Gallo, J.M.; Ramanathan, R.; Muralidhara, S. and Bruckner, J.V. (1991): Physiological pharmacokinetic modeling of inhaled trichloroethylene in rats. Toxicol. Appl. Pharmacol., 110: 303-314.

[14] Lash, L.H.; Fisher, J.W., Lipscomb, J.C. and Parker, J.C. (2000a): Metabolism of trichloroethylene. Environ. Health Perspect., 108: 177-200.

[15] Goeptar, A.R.; Commandeur, J.M.; Van-Ommen, B.; Van-Bladeren, P.J. and Vermeulen, N.E. (1995): Metabolism and kinetics of trichloroethylene in relation to toxicity and carcinogenicity. Relevance of the mercapturic acid pathway. Chem. Res. Toxicol., 8: 3-21.

[16] Terada, M. and Nishimura, H. (1975): Mitigation of caffeineinduced teratogenecity in mice by prior chronic caffeine ingestion. Teratology, 12: 79 -82.

[17] Tucker, A.; Sanders, V.; Barnes, D.; Bradshaw, T.; White, K.J.R.; Sain, L.; Borzelleca, J. and Munson, A. (1982): Toxicology of trichloroethylene in the mouse. Toxicol. Appl. Pharmacol., 62: 351357.

[18] Taylor, P. (1986): Practical teratology. Acad. Press Inc., London.

[19] Schwetz, B.; Leong, B. and Gehring, P. (1975): The effect of maternally inhaled trichloroethylene, perchloroethylene, methyl chloroform, and methylene chloride on embryonal and fetal development in mice and rats. Toxicol. Appl. Pharmacol., 32: 84-96. 
[20] Mohamed, M.I.E. (1996): The effect of alcohol and nicotine on fertility, pregnancy and development in albino mice. Ph.D. Thesis, Faculty of Science, Ain Shams Univ.

[21] Stuckey, E. and Berrey, C.L. (1984): The effects of high dose sporadic (binge) alcohol intake in mice. J. Pathol., 142(3): 175-180.

[22] Ebied, H.L. (2002): Teratogenic effect of methomyl on pregnant mice and their fetuses. M.Sc. Thesis, Faculty of Science, Suez Canal Univ., Egypt.

[23] Mazzullo, M.; Bartoli, S.; Bonora, B.; Colacci, A.; Lattanzi, G.; Niero, A.; Silingardi, P. and Grilli, S. (1992): In vivo and In vitro interaction of trichloroethylene with macromolecules from various organs of rat and mouse. Res. Comm. Chem. Pathol. Pharmacol., 76: 192-208.

[24] Wu, K.L. and Berger,T. (2007): Trichloroethylene metabolism in the rat ovary reduces oocyte fertilizability. Chem. Biol. Interact., 170: $20-30$

[25] Wu, K. and Berger, T. (2008): Ovarian gene expression is stable after exposure to trichloroethylene. Toxicol. Lett., 177: 59-65.

[26] Essia, M.I.; Shahin, M.A. and Mansour, M.A. (2007): Teratogenic effects of N-nitrosodimethylamine on pregnant rats and their fetuses. J. Egypt. Ger. Soc. Zool., 54(B): 19-50.

[27] Steele-Goodwin, L.; Pravacek, T.L. and Carmichael A.J. (1996): Trichloroethylene metabolism in vitro: an EPR/Spin trapping study. Human Exp. Toxicol., 15: 878-884.

[28] Ni, Y.; Wong, T. and Fu, P.P. (1996): Mouse liver microsomal metabolism of chloral hydrate, trichloroacetic acid and trichloroethanol leading to induction of lipid peroxidation via a free radical mechanism. Drug Metab. Dispos., 24: 81-90.

[29] Cai, H. and Guengerich, F.P. (2001): Reaction of trichloroethylene and trichloroethylene oxide with cytochrome P450 enzymes: inactivation and sites of modification. Chem. Res. Toxicol., 14(4): 451458.

[30] Khan, S.; Priyamvada, S.; Khan, A.S.; Khan, W.; Farooq, N.; Khan, F. and Yusufi, K.A. (2009): Effects of trichloroethylene (TCE) toxicity on enzymes of carbohydrate metabolism, brush border membrane and oxidative stress in kidney and other rat tissues. Food and Chem. Toxicol., 47: 1562-1568.

[31] Stadtman, E.R. and Oliver, C.N. (1991): Metal-catalyzed oxidation of proteins. Physiological consequences. J. Biol. Chem., 266(4): 2005-2008.

[32] Theiler, K. (1989): The house mouse. Springer Verlag, Berlin, Heidelberg, New York.

[33] Laham, S. (1970): Studies on placental transfer: Trichlorethylene. Ind. Med. Surg., 39: 46-49.

[34] Withey, J. and Karpinski, K. (1985): The fetal distribution of some aliphatic chlorinated hydrocarbons in the rat after vapor phase exposure. Biol. Res. Pregnancy Perinatol., 6: 79-88.

[35] Ganong, W.F. (1995): Review of medical physiology. $17^{\text {th }}$ Edn., Lange Medical Publication, California. 